\title{
The on-line measurement of greenhouse gases emitted by a reactor for nitrogen removal from digested zootechnical slurry
}

\author{
P. Battistoni ${ }^{1}$, S. Carletti ${ }^{2}$ \& G. Passerini ${ }^{2}$ \\ ${ }^{I}$ Department of Materials, Environmental Sciences and Urban Planning, \\ Marche Polytechnic University, Italy \\ ${ }^{2}$ Department of Industrial Engineering and Mathematical Sciences, \\ Marche Polytechnic University, Italy
}

\begin{abstract}
Anaerobic digestion can be considered the choice treatment for most organic waste but digested bulk contains a little percentage of carbon-based compounds and a big load of nitrogen-based compounds. This imbalance is particularly evident for digested zootechnical slurry that originally contains high amounts of nitrogen so that its use as fertilizer had to be limited. nitrogen removal is necessary to achieve a good quality fertilizer so to avoid its stockpiling or misuse. The choice treatment for nitrogen removal is obtained though reactors that apply the so called "Alternate Oxic/Anoxic" treatments. These treatments produce, especially during oxidation (i.e. Oxic phase), emissions of airborne substances including pollutants and greenhouse gases. We found that the literature on this topic is limited and there are no uniformly accepted values for pollutant emissions. Also it is hard to estimate the emissions due to the particular variety of slurry with high nitrogen content and the countless types of treatment plants. The aim of our work was evaluating and estimating the emissions of greenhouse gases $(\mathrm{CO} 2, \mathrm{CH} 4, \mathrm{~N} 2 \mathrm{O})$ and nitrogen oxides (NOX) from such nitrogen removal reactors. We monitored a mid-size pilot reactor that performs a continuous alternate Oxic/Anoxic biological process to perform an on-line measurement of emissions produced. The reactor was designed and used to reduce the nutrient loads from the supernatants of anaerobically digested swine and cattle flows. An ad hoc monitoring station has been designed and assembled. Its measurement ranges have been specified mainly on the basis of the few values reported in literature. The air supply of platform is intermittent since aeration occurs only in Oxic phase. Thus we have tested several caps for the
\end{abstract}


tanks and different methods to perform off-gas analysis. Here we present the preliminary results of the system start-up that included a measurement campaign of six months, and a tentative calculation method to evaluate pollutant emissions as a function of slurry composition and digestion.

Keywords: environmental impact, agricultural waste.

\section{Introduction}

Anaerobic digestion can be considered the choice treatment for most organic waste such as organic fraction of municipal solid waste, vegetable scraps, manure etc. In fact, this treatment has an almost null impact on the environment and produces an amount of biogas that can be employed as fuel. By doing so, we reduce the volume of waste being sent to landfill, and therefore decrease methane emissions produced by its decay. Additional environmental gains include improvements in water quality and air quality compared with current practices of waste management. Digested organic waste has always been regarded as a good fertilizer but concerns have been advised due to its unbalanced blend: usually it contains a little bulk of carbon based compounds and a big load of nitrogen based compounds. This imbalance is particularly evident for digested zootechnical slurry that originally contains high amounts of nitrogen so that its use as fertilizer had to be limited. These characteristics must be taken into account to implement a hypothetical solution as removal and/or recover of some nutrients according with the European Directive 91/676/EEC. The traditional biological nitrogen removal process involves the oxidation of ammonium to nitrate, followed by reduction through an organic carbon source to nitrogen gas. In this pathway, nitrite is an intermediate of both steps.

In wastewater treatment plants, we can assume that nitrification is mostly performed by autotrophic bacteria that use ammonium (polyatomic ion $\mathrm{NH}_{4}{ }^{+}$) or nitrite (polyatomic ion $\mathrm{NO}_{2}^{-}$) as energy source and carbon dioxide $\mathrm{CO}_{2}$ as carbon source [1]. These reactions are triggered by few groups of microorganisms like ammonium oxidizing bacteria (AOB), that convert ammonium into nitrite (i.e. "nitritation") and nitrite oxidizing bacteria (NOB), that convert nitrite into nitrate (polyatomic ion $\mathrm{NO}_{3}{ }^{-}$).

The denitrification by heterotrophic microorganisms (HET) takes place in the anoxic phase when nitrate $\mathrm{NO}_{3}^{-}$is reduced to nitrite $\mathrm{NO}_{2}^{-}$, nitric oxide $\mathrm{NO}$, nitrous oxide $\mathrm{N}_{2} \mathrm{O}$ and, finally, molecular nitrogen $\mathrm{N}_{2}$ in absence of oxygen. Also in this process, we can split the course into two phases: in the first step nitrate turns into nitrite and the second step nitrite turns into nitrogen gas through the so-called "denitritation" process. Since nitrate is used as an electron acceptor for the denitrification reaction, a sufficient amount of carbon is required to achieve effective nitrogen removal.

A complete nitrogen removal could be achieved preventing the complete oxidation of ammonium, by discontinuing its conversion to nitrate. This nitrite pathway may yield up to a $25 \%$ reduction in aeration and $40 \%$ reduction in COD requirements [2]. It can be an economically feasible alternative to the conventional process. 
A medium size platform has been set up, to check and optimise such processes by investigating the performances obtainable with a continuous alternate oxic/anoxic biological process optimised to reduce the nutrient loads from the supernatants produced by anaerobic digestion of swine and cattle flows. The alternate process is characterized by a continuous influent flow and subject to oxic and anoxic phases automatically synchronized. Software defines the switch between aerobic phase and anoxic phase and tunes the time span of the two phases [3].

\section{Greenhouse gases emissions from nitrogen removal reactors}

Each of the monitored pollutants has its own mechanism of formation. Nitrous oxide $\mathrm{N}_{2} \mathrm{O}$ and nitrogen monoxide $\mathrm{NO}$ develop during the denitritation phase, being intermediates of the reaction through which nitrite is reduced to molecular nitrogen.

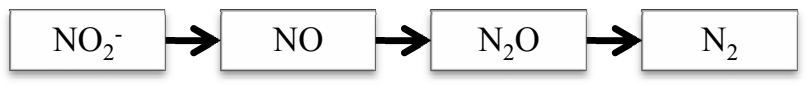

The nitritation is produced by means of ammonium oxidizing bacteria (AOB), namely by two groups of microorganisms. The first step is catalysed by ammonia mono-oxygenase (AMO). At this stage, $\mathrm{NH}_{4}{ }^{+}$is oxidized to hydroxylamine $\mathrm{NH}_{2} \mathrm{OH}$, through the reduction of one atom of molecular oxygen $\mathrm{O}_{2} \cdot \mathrm{NH}_{2} \mathrm{OH}$ is an intermediate, which is oxidized to $\mathrm{NO}_{2}^{-}$by hydroxylamine oxidoreductase (HAO).

$\mathrm{N}_{2} \mathrm{O}$ and $\mathrm{NO}$ are released from the nitrification reaction as a by-product of ammonium oxidation under aerobic conditions by nitrifiers [4]. Some AOB can reduce nitrite and release $\mathrm{NO}$ and $\mathrm{N}_{2} \mathrm{O}$.

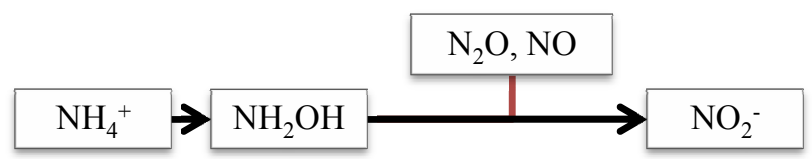

The second step of nitrification is catalysed by Nitrite Oxidizing Bacteria, NOB, without detectable intermediate. According to Kampschreur et al. [1], there are three main pathways for $\mathrm{N}_{2} \mathrm{O}$ production: hydroxylamine oxidation i.e. production of $\mathrm{N}_{2} \mathrm{O}$ as by-product of biological hydroxylamine oxidation, or by chemical reaction between nitrite and hydroxylamine; nitrifier denitrification i.e. reduction of $\mathrm{NO}_{2}^{-}$by $\mathrm{AOB}$ in combination with ammonia or hydrogen as electron donor; heterotrophic denitrification since $\mathrm{N}_{2} \mathrm{O}$ is an inter-mediate in the denitrification process and incomplete Denitrification can lead to these emissions. 
The nitric oxide formation pathway is similar to $\mathrm{N}_{2} \mathrm{O}$, but there are fewer reports in the literature, as the emissions of this pollutant from the water treatment sector have lower impact compared to the emissions from other anthropogenic sectors. Stuven and Bock [5] report that biological treatment of nitrogen-rich wastewater is not a significant source for pollution of the atmosphere compared with $\mathrm{NO}_{\mathrm{X}}$ due to industrial areas. Moreover, $\mathrm{N}_{2} \mathrm{O}$ emissions are predicted to be higher than the nitrogen oxide emission since NO is an intermediate, and $\mathrm{N}_{2} \mathrm{O}$ is the final product of the $\mathrm{AOB}$ denitrification pathway.

Most of $\mathrm{N}_{2} \mathrm{O}$ and $\mathrm{NO}$ emissions occur in the aeration phase. This, however, does not mean that $\mathrm{N}_{2} \mathrm{O}$ is only produced in the aerated compartments. It can also be produced in the anoxic stage and subsequently be stripped to the gas phase in an aerated compartment [1].

For the process of partial nitrification via nitrite, the key point is to favour the nitritation process and, at the same time, to inhibit or suppress the nitratation process in order to have a biomass enriched in ammonium oxidizing bacteria and poor in nitrite-oxidizing bacteria [2].

Emissions of carbon dioxide derive from the conversion of organic matter; part of $\mathrm{CO}_{2}$ may be consumed during reactions.

Methane is prevalently emitted during sludge handling and anaerobic digestion but some emissions may also occur during alternate cycles.

\subsection{Survey of literature data}

The results of both full-scale and laboratory experiments are quite few and there are no uniformly accepted values for pollutant emissions. The highest values are recorded in the processes of wastewater treatment with high nitrogen load, usually swine slurry, rather than in municipal waste water.

The concentration of airborne substances (usually expressed in ppm) is apparently influenced by the volume over which the analysis is carried out, by type of coverage, and by the settings of aerobic phase. The air flow supplied can lead to increases in concentration values (the air stripping from the liquid phase may be intensified) or decreases (as the pollutants are diluted in a greater volume of air). A more accurate index is the ratio between $\mathrm{N}_{2} \mathrm{O}$ emitted and the input nitrogen load.

The concentrations of $\mathrm{N}_{2} \mathrm{O}$ vary between $25 \mathrm{ppm}$ [7] and $200 \mathrm{ppm}$ [6], with two peaks of $750 \mathrm{ppm}$ and 4,500 ppm detected, respectively, in the nitritation and annamox process in Dokhaven-Sluisjesdijk plant. In this case precise operating conditions have been imposed: a low aeration flow rate and a decrease in dissolved oxygen concentration favor an increase in $\mathrm{N}_{2} \mathrm{O}$ production; under normal operating conditions the values are more limited. Due to the strong fluctuations in $\mathrm{N}_{2} \mathrm{O}$ level, only time-dependent measurements allow a reliable estimate of emissions [6].

Nitrogen monoxide concentrations are an order of magnitude lower than nitrous oxide, with a maximum value of $80 \mathrm{ppm}$, measured in a full-scale plant with high nitrogen content [6]. 
Focusing on nitrogen load in input matter, the $\mathrm{N}_{2} \mathrm{O}$ emissions vary from $0.035 \%$ [8] to $5 \%$ in a grab sample collected in the B-stage nitrogen removal of Dokhaven-Sluisjesdijk [6]. The NO emissions range from $0.028 \%$ [9] to $0.2 \%[6]$.

\subsection{Nitrogen oxide emissions from a municipal wastewater plant}

A preliminary measurement campaign was carried out in the full-scale device for biological nutrients removal of a municipal wastewater treatment plant of a midsize city. The purpose was to quantify roughly the emissions of nitrogen oxides from biological process of alternate cycles. Most of influent nitrogen load was due to ammonia. Nitrites and nitrates were nearly absent. The test equipment consisted of a closed chamber floating on the free surface of the tank. Sample air grabs were taken from the coverage, during the nitrification phase, and measured in laboratory tests. The collected samples were monitored by a Nitrogen Oxides Analyzer 8841 (Rancon Instruments). Figure 1 shows the highest concentrations of $\mathrm{NO}$ and $\mathrm{NO}_{2}$ measured in three tests repeated over three days.

All samples have a higher concentration of nitrogen monoxide compared to the nitrogen dioxide. The results of the second sample are higher since the sampling method had changed, to prevent dilution effects.

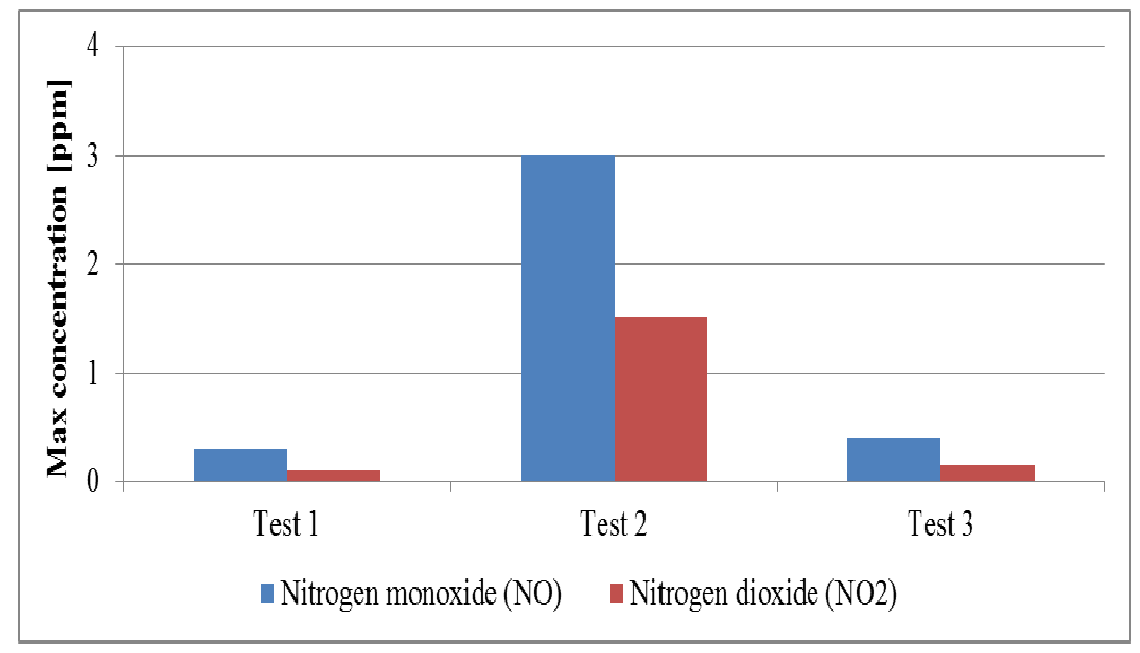

Figure 1: Maximum values of $\mathrm{NO}$ and $\mathrm{NO} 2$ measured by the analyser for the three gas samples taken in Jesi wastewater plant.

\subsection{Choice of measuring range}

The full-scale values and the related instrument sensitivity for each pollutant have been selected according to literature data and the results of the tests performed in the wastewater treatment plant. Such values are shown in table 1. 
Table 1: Instrument full scale and sensitivity.

\begin{tabular}{c|c|c}
\hline Pollutant & Full scale & $\begin{array}{c}\text { Detectable minimum }(2 \% \\
\text { full scale })\end{array}$ \\
\hline Nitrous oxide $\left(\mathrm{N}_{2} \mathrm{O}\right)$ & $200 \mathrm{ppm}$ & $4 \mathrm{ppm}$ \\
\hline Methane $\left(\mathrm{CH}_{4}\right)$ & $50 \mathrm{ppm}$ & $1 \mathrm{ppm}$ \\
\hline Carbon dioxide $\left(\mathrm{CO}_{2}\right)$ & $3 \%$ & $600 \mathrm{ppm}(0.06 \%)$ \\
\hline Nitrogen monoxide $(\mathrm{NO})$ & $50 \mathrm{ppm}$ & $1 \mathrm{ppm}$ \\
\hline Nitrogen oxides $\left(\mathrm{NO}_{\mathrm{X}}\right) *$ & $50 \mathrm{ppm}$ & $1 \mathrm{ppm}$ \\
\hline * Nitrogen dioxide $\mathrm{NO}_{2}$ is calculated from $\mathrm{NO}_{\mathrm{X}}$ and $\mathrm{NO}$ values: $\mathrm{NO}_{2}=\mathrm{NO}_{\mathrm{X}}-\mathrm{NO}$ \\
\hline
\end{tabular}

\section{Sampling and analysing instruments}

To perform on-line measurement we choose the "MIR9000" analyser produced by Environment S.A. The MIR9000 analyser is capable to perform continuous measurement of 1 to 16 substances on gaseous samples. The analysis of most substances is based on absorption spectroscopy. An optical ray is emitted by the IR source (fig. 2), passes through the measurement chamber, and is focused on an IR detector. Each gas, which is present on the path of the optical ray, absorbs the latter at defined wavelengths that are specific. An interference filter, which defines a specific wavelength area, is positioned on the optical path above the measurement chamber.

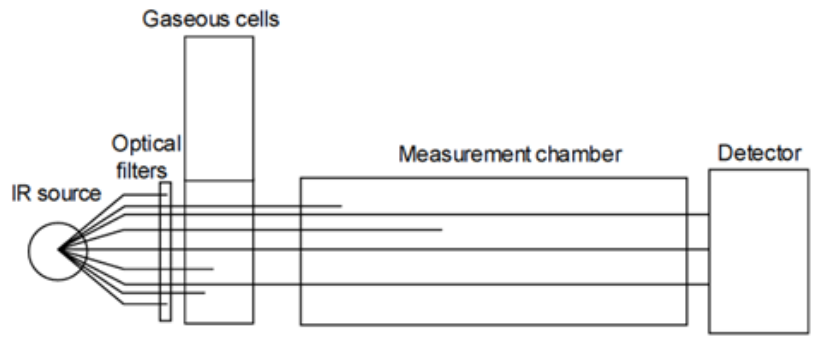

Figure 2: $\quad$ Measurement principle of infrared spectroscopy with correlation.

According to the Beer Lambert law, we obtain

$$
\frac{\mathrm{I}}{\mathrm{I}_{0}}=e^{-k L \mathrm{c}}=>\mathrm{c}=-\frac{1}{k L} \ln \left(\frac{\mathrm{I}}{\mathrm{I}_{0}}\right)
$$

where $I_{0}$ is the energy received by the detector when there is no gas in the measurement chamber, I is the energy received by the detector when gas is present in the measurement chamber, $\mathrm{k}$ is a coefficient depending on the gas and the wavelength, $\mathrm{L}$ is the length of the optical path and $\mathrm{c}$ is the concentration.

Since there is not just one wavelength behind an interference filter, but several wavelengths, the equation becomes:

$$
\mathrm{c}=f\left(\frac{\mathrm{I}}{\mathrm{I}_{0}}\right)
$$


The function $f$ is always close to a logarithm and can be linearized very precisely by a polynomial. It is very difficult to measure $\mathrm{I}$ and $\mathrm{I}_{0}$ simultaneously. Due to correlation by a gaseous filter, this problem can be avoided: a cell filled with highly concentrated gas that needs to be measured and a cell filled with nitrogen, which does not absorb any wavelength, are positioned on the optical path alternately. The highly concentrated gas, which is in the cell called the reference cell, absorbs all wavelengths that are specific to it. Even if gas molecules are present in the measurement chamber and on the optical path, all wavelengths that should have been absorbed by them have already been absorbed. Therefore, the energy received by the detector can be considered constant and serves as IR bias for this gas, in spite of its dependence on other phenomena such as the power of the infrared source, the presence of particles and their opacity. Some milliseconds later, the cell filled with nitrogen is positioned on the optical path. Absorption of the infrared energy is due to the gas in the measurement chamber, according to the Beer Lambert law. Therefore, after absorption by the gas, the ratio between the reference energy and the energy ' $\mathrm{I}$ ' is known at any moment. Hence, the gas concentration can be deduced, using the formula

$$
c=f\left(\frac{\mathrm{I}}{\mathrm{I}_{\mathrm{R}}}\right)
$$

where $\mathrm{I}$ is the energy received by the detector when there is nitrogen in the gaseous cell and the sample gas is present in the measurement chamber and $I_{R}$ is the energy received by the detector, when there is a highly concentrated gas in the gaseous cell.

To correct any further deviation, the monitor readjusts its zero periodically, which means that it defines the ratio between the reference energy and the measurement energy when there is no gas on the optical path. A ray emitted by an infrared source and measured by a detector passes through the optical chamber. The semi-conducting detector receives the optical beam after it has gone through a series of interference filters and gaseous cells, mounted on a wheel turning at high speed. In our configuration, the measurement chamber of the zero reference it is not filled with reconstituted air but with compressed, filtered, and dehumidified ambient air. Hence, the measured values are relative emissions.

To measure nitric oxides (NOx) concentrations, Chemi-Luminescence Detectors (CLD) represent the standard method and it is employed by the MIR9000 analyser. The analyser operates on the principle that nitrogen oxide (NO) will emit light in the presence of highly oxidizing ozone molecules according to

$$
\begin{gathered}
\mathrm{NO}+\mathrm{O}_{3} \rightarrow \mathrm{NO}_{2}^{*}+\mathrm{O}_{2} \\
\mathrm{NO}_{2}^{*} \rightarrow \mathrm{NO}_{2}+\mathrm{hv}
\end{gathered}
$$


The return to a fundamental electronic state of the excited $\mathrm{NO}_{2}^{*}$ molecules is made by luminous radiation in a 600-1200 $\mathrm{nm}$ spectrum. This energy can be lost by shock with some molecules found in the sample (quenching). In order to obtain a better chemical luminous yield, the probability of collision is reduced by lowering the pressure in the reaction chamber.

The reaction chamber is separated from the detector by an optical filter, which selects only the radiation of wavelengths greater than $610 \mathrm{~nm}$, thus eliminating interferences due to hydrocarbons. The radiation measurement is made by a photo-multiplier (PM).

In order to be measured by CLD, the $\mathrm{NO}_{2}$ must be first transformed into NO. A molybdenum oven carries out this reduction according to:

$$
2 \mathrm{NO}_{2} \stackrel{\mathrm{Mo}}{\rightarrow} 2 \mathrm{NO}+\mathrm{O}_{2}
$$

The measurement is done in three cycle steps. During the reference cycle the sample is led into a pre-reaction chamber to be blended with ozone. The NO molecules contained in the gas are oxidized into $\mathrm{NO}_{2}$ before entering the reaction chamber. The signal thus measured by the PM, without chemiluminescence, may be considered as "zero air" measurement and used as reference signal. During the $N O$ cycle the sample is directly led into the measurement chamber where NO oxidation by ozone is carried out. The signal measured by the PM is proportional to the number of NO molecules contained in the sample. During the $N O_{X}$ cycle the sample flows through the converter oven then it is blended with ozone inside the reaction chamber. The signal measured by the PM is proportional to the number of $\mathrm{NO}$ and $\mathrm{NO}_{2}$ (from $\mathrm{NO}$ reduction) molecules contained in the sample.

\section{Measurement procedures}

An external pump creates a vacuum pressure that allows the suction from the sampling point. The gaseous sample is divided and channelled to the two measurement chamber: infrared chamber (infrared spectroscopy with correlation) and CLD chamber (chemi-luminescent measurement chamber). Two solenoid valves allow changing the inlet gas: zero air inlet, for the zero reference cycle, and span inlet, for the calibration.

As already noticed, the device does not use pure air from an air zero generator, but takes ambient air; therefore, the zero of each pollutant is equal to its background concentration in the atmosphere. An oil free compressor, with membrane air dryer, supplies air for each cycle of zero reference (every 3 hours) and for the ozone generator. The system is composed by a cooler with forced ventilation, a double 5-micron and 0.01-micron filtration system to guarantee the best air purity, and a fully automatic membrane dryer. High concentrations of water vapour may distort the measurements and condensed vapour may damage the instrument. Dehumidification is also required because the zero air is used for the ozone production. The ozone generator is formed by two cylindrical, coaxial electrodes. The internal electrode, made of a stainless steel cylinder, is connected 
to the high voltage circuit $(4.5 \mathrm{KV})$. The external electrode is a glass cylinder covered with a thin metal sheet connected to the ground. The dry air circulating between the electrodes is oxidized and transformed in part into ozone.

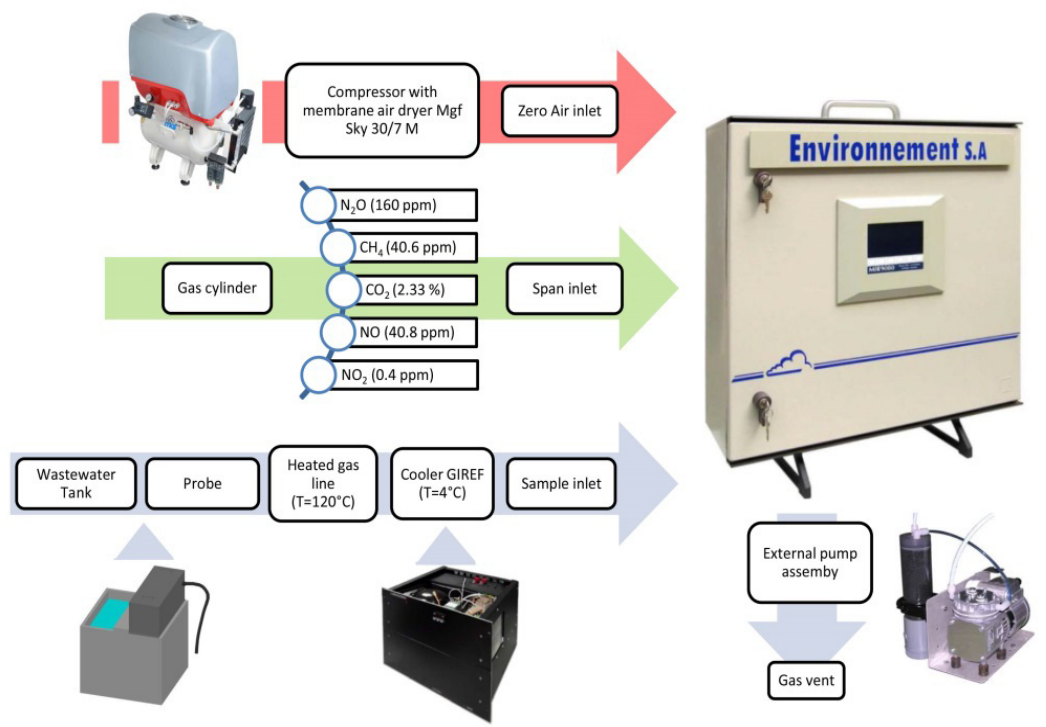

Figure 3: Flow diagram of MIR9000CLD analyser.

The air sample is taken by a probe. Downstream of the sampling point a heated gas line keeps gas temperature high, so that any condensed matter, like sprays and foams, cannot reach the measurement chamber of the instrument. The gas line is set to $120^{\circ} \mathrm{C}$ and is maintained by a temperature controller. However, at this temperature the sample could not be analysed by the MIR9000CLD. For this reason, a cooler decreases gas temperature to a constant $4^{\circ} \mathrm{C}$ also to reduce water vapour content.

The sampling system was conceived and tuned to take into account several other issues. Between all problems, the biological reactor is provided with blower and mixer to alternate oxic and anoxic phases. Such phases are automatically regulated based on signals coming from a dissolved oxygen probe and an oxidation-reduction potential probe. Thus, the cycling of supply airflow is not constant. In a first stage, an almost sealed case has been tested. The case was made by two PVC caps, each occupying half of tank and the probe was incorporated in one of these. However, the tanks of full-scale plants are uncovered and we found that the coverage could interfere with the release rate of molecular nitrogen $\mathrm{N}_{2}$.

Thus, we designed a new probe holder to reduce interferences with the processes. The new probe frame is a cylinder floating on the surface of the mixed liquor. The surface involved is about $10 \%$, so we can assume that the cover does not influence the biological processes. Since the PVC board is dipped for few 
centimetres, we can assume that there is no exchange between air trapped within the coverage and the external air. On the top of the cover, a PVC tube has been inserted and the probe has been connected at about half height, as shown in Figure 4.

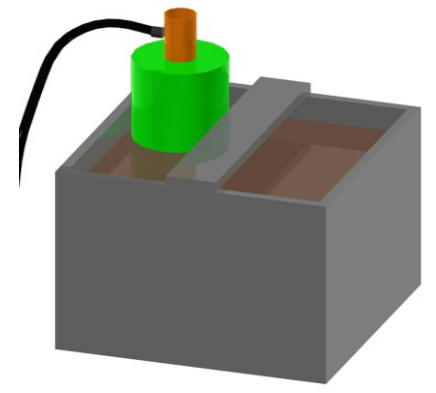

Figure 4: Gas sampling system.

\section{Results and discussion}

The trends of airborne pollutants are related to the biological process phases: the highest emissions are under aerobic condition.

In fig. 5 and 6 we report daily maximum values of airborne pollutants sampled over the period from June 14 to August 31 2013. From 28 June to July 14 there are no measurements due to a massive presence of foams in the reactor. The maximum values of nitrous oxide and methane are nearly constant, while nitrogen oxides and carbon dioxide decrease after measurement shutdown of July (Fig. 6).

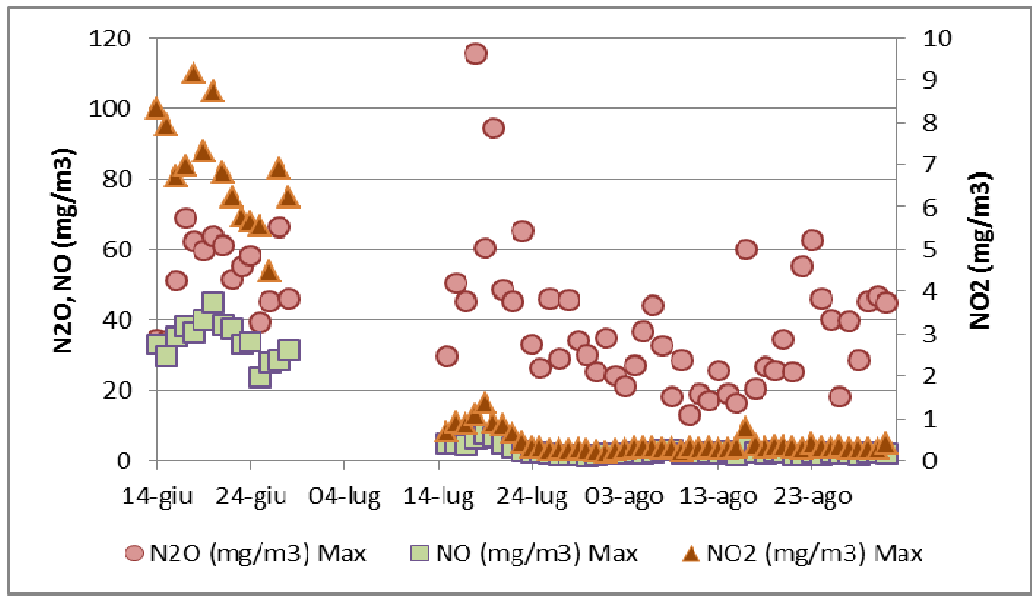

Figure 5: Maximum values of nitrous oxide, nitrogen monoxide and nitrogen dioxide $[\mathrm{mg} / \mathrm{m} 3]$ for each day from June 14 to August 31. 


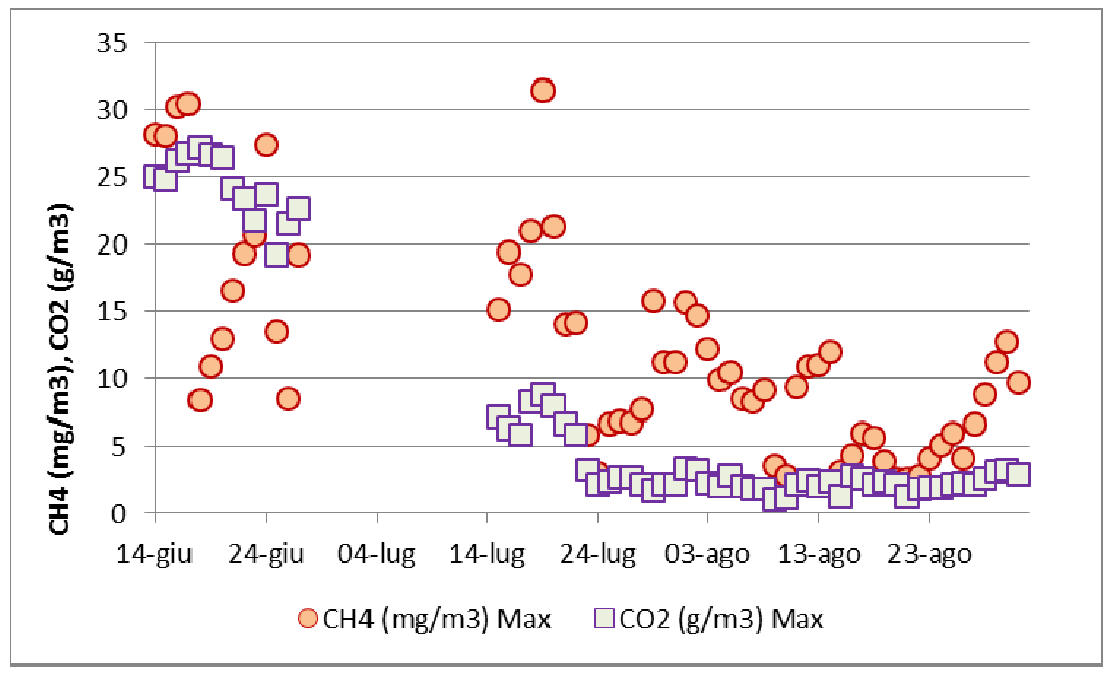

Figure 6: Maximum values of methane $[\mathrm{mg} / \mathrm{m} 3]$ and carbon dioxide $[\mathrm{g} / \mathrm{m} 3]$ for each day from June 14 to August 31.

The production of nitrogen compounds $\left(\mathrm{N}_{2} \mathrm{O}, \mathrm{NO}, \mathrm{NO}_{2}\right)$ compared to the nitrogen load in the liquid phase is obtained by dividing daily average values by inlet ammonia load. The daily values are shown in Figure 7.

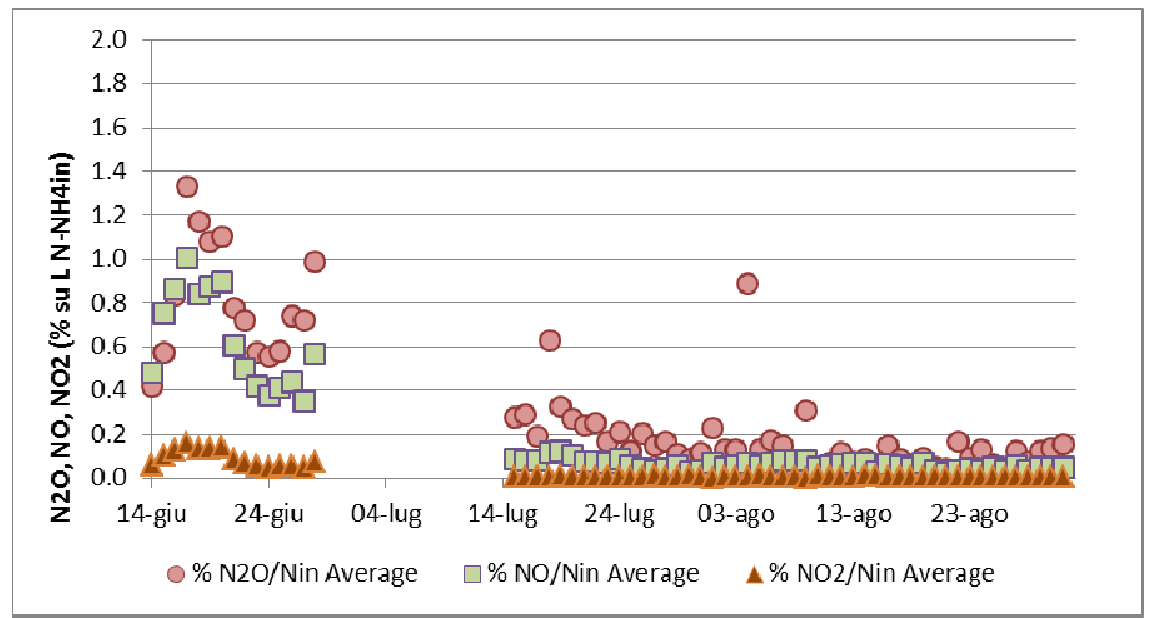

Figure 7: Daily ratio values of emissions to input nitrogen load [\%] from June 14 to August 31. 


\section{Conclusions}

Preliminary results of further sampling led to the same low emissions obtained in August. The measurement shutdown of July, due to the presence of foam, does not allow understanding the lower emission levels.

The measuring ranges of MIR9000CLD are well calibrated for methane, carbon dioxide and nitrous oxide emissions during the first part of monitoring campaign while, after August, are overestimated. Unquestionably, the low emission levels in this second period are mainly due to a change in the inlet sewage (from swine to cattle) but could also be triggered by operating conditions of the treatment process. The emissions of nitrous oxide and nitrogen monoxide compared to the inlet ammonia load are consistent with the literature data. Nitrogen dioxide never exceeds $0.2 \%$ of the input nitrogen load, and therefore its emission can be neglected.

\section{Acknowledgment}

This work has been supported by Fondazione Cariverona of Italy.

\section{References}

[1] Kampschreur, M. J., Temmink, H., Kleerebezem, R., Jetten, M.S.M. \& van Loosdrecht, M.C.M. Nitrous oxide emission during wastewater treatment, in Water Research, 43, 4093-4103, 2009.

[2] Rajagopal, R. \& Béline, F. Nitrogen removal via nitrite pathway and the related nitrous oxide emission during piggery wastewater treatment, in Bioresource Technology, 102, 4042-4046, 2011.

[3] Santinelli, M., Eusebi, A. L., Santini, M. \& Battistoni, P. The zootechnical anaerobic supernatants: nutrient removal by a biological advanced process, in Industrial \& Engineering Chemistry Research, 51, 5490-5496, 2012.

[4] Hwang, S., Jang, K., Jang, H., Song, J. \& Bae, W. Factors affecting nitrous oxide production: a comparison of biological nitrogen removal processes with partial and complete nitrification, in Biodegradation, 17, 19-29, 2006.

[5] Stuven, R. \& Bock, E. Nitrification and denitrification as a source for NO and NO2 production in high-strength wastewater, in Water Research, 35, 1905-1914, 2001.

[6] Kampschreur, M.J., van der Star, W.R.L., Wielders, H.A., Mulder, J.W., Jetten, M.S.M. \& van Loosdrecht, M.C.M. Dynamics of nitric oxide and nitrous oxide emission during full-scale reject water treatment, in Water Research, 42, 812-826, 2008.

[7] Kampschreur, M.J., Tan, N.C.G., Kleerebezem, R., Picioreanu, C., Jetten, M.S.M. \& van Loosdrecht, M.C.M. Effect of dynamic process conditions on nitrogen oxides emission from a nitrifying culture, in Environmental Science \& Technology, 42, 429-435, 2008. 
[8] Czepiel, P., Crill, P. \& Harriss, R. Nitrous Oxide Emissions from Municipal Wastewater Treatment, in Environmental Science \& Technology, 29, 2352-2356, 1995.

[9] Fuerhacker, M., Bauer, H., Ellinger, R., Sree, U., Schmid, H., Zibuschka, F. \& Puxbaum, H. Relationship between release of nitric oxide and $\mathrm{CO} 2$ and their dependence on oxidation reduction potential in wastewater treatment, in Chemosphere, 44, 1213-1221, 2001.

[10] IPCC Guidelines for National Greenhouse Gas Inventories. Vol. 5: Waste; chapter 6: Wastewater treatment and discharge, 2006. 